US Army Corps

of Engineers

Prepared for the U.S. Army Corps of Engineers, Portland District,

under an Interagency Agreement with the U.S. Department of Energy

Contract DE-AC05-76RL01830

\title{
Development of a
}

Conceptual Chum Salmon

Emergence Model for Ives Island

\section{Final Report}
CJ Murray
DR Geist
Y-J Bott
EV Arntzen
MA Nabelek

February 2011

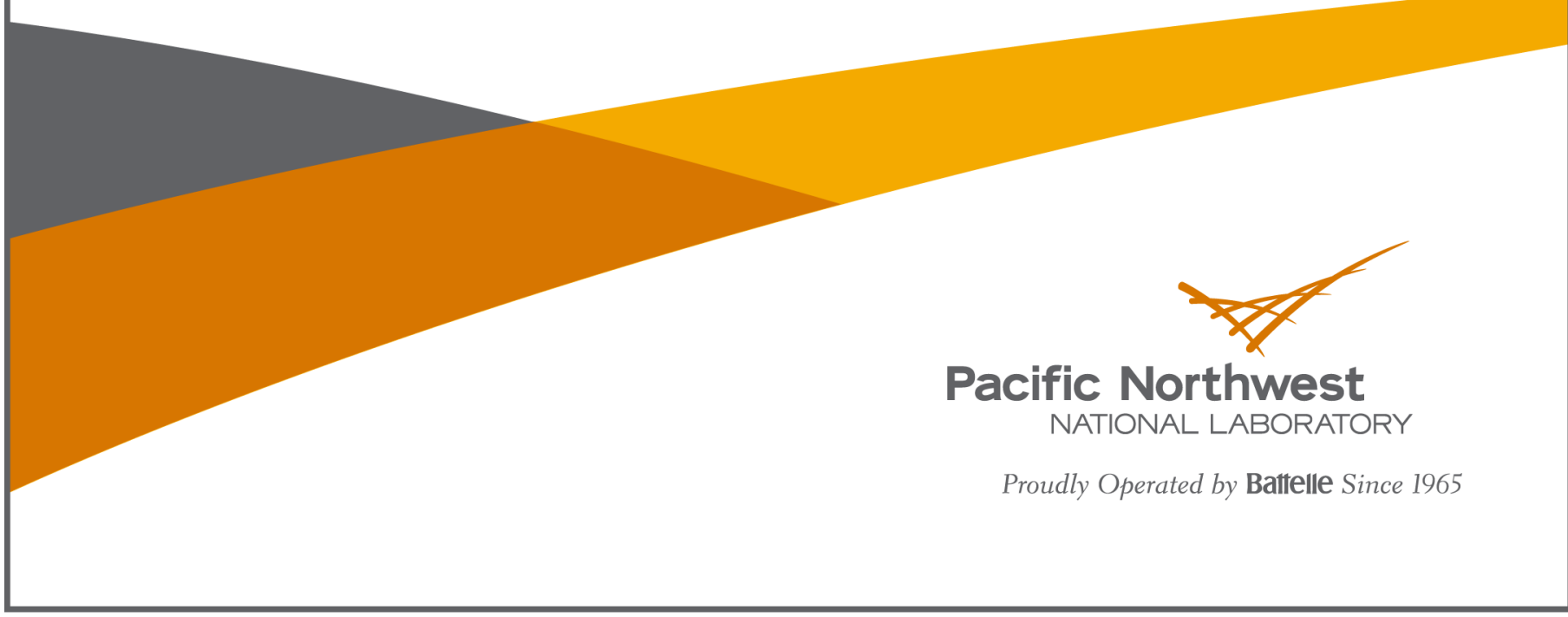




\title{
DISCLAIMER
}

This report was prepared as an account of work sponsored by an agency of the United States Government. Neither the United States Government nor any agency thereof, nor Battelle Memorial Institute, nor any of their employees, makes any warranty, express or implied, or assumes any legal liability or responsibility for the accuracy, completeness, or usefulness of any information, apparatus, product, or process disclosed, or represents that its use would not infringe privately owned rights. Reference herein to any specific commercial product, process, or service by trade name, trademark, manufacturer, or otherwise does not necessarily constitute or imply its endorsement, recommendation, or favoring by the United States Government or any agency thereof, or Battelle Memorial Institute. The views and opinions of authors expressed herein do not necessarily state or reflect those of the United States Government or any agency thereof.

\author{
PACIFIC NORTHWEST NATIONAL LABORATORY \\ operated by \\ BATTELLE \\ for the \\ UNITED STATES DEPARTMENT OF ENERGY \\ under Contract DE-AC05-76RL01830
}

Printed in the United States of America

\author{
Available to DOE and DOE contractors from the \\ Office of Scientific and Technical Information, \\ P.O. Box 62, Oak Ridge, TN 37831-0062; \\ ph: (865) 576-8401 \\ fax: $(865) 576-5728$ \\ email: reports@adonis.osti.gov
}

\begin{abstract}
Available to the public from the National Technical Information Service, U.S. Department of Commerce, 5285 Port Royal Rd., Springfield, VA 22161 ph: (800) 553-6847 fax: $(703) 605-6900$

email: orders@ntis.fedworld.gov

online ordering: http://www.ntis.gov/ordering.htm
\end{abstract}

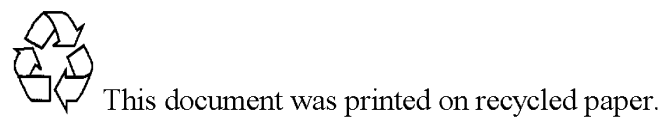

(9/2003) 


\title{
Development of a Conceptual Chum Salmon Emergence Model for Ives Island
}

\section{Final Report}

\author{
CJ Murray $\quad$ Y-J Bott \\ DR Geist \\ MA Nabelek \\ EV Arntzen
}

February 2011

Prepared for

the U.S. Army Corps of Engineers, Portland District, under an Interagency Agreement with

the U.S. Department of Energy

Contract DE-AC05-76RL01830

Pacific Northwest National Laboratory

Richland, Washington 99352 


\section{Summary}

The objective of this project was to develop a conceptual model for the U.S. Army Corps of Engineers, Portland District, that can be used to predict the timing of chum salmon (Oncorhynchus keta) emergence in the Ives Island area. Researchers at the Pacific Northwest National Laboratory developed the model using real-time hourly temperature data from three locations in the Ives Island spawning area that were instrumented with paired hyporheic and river sensors beginning in 2003. These data were supplemented by additional temperature data collected in the Ives Island area during 2006-2007, including 5 additional paired hyporheic and river sensors and 32 hyporheic sensors that measured temperature at approximately $15 \mathrm{~cm}$ below the bed surface of the Columbia River.

Using these data, we calculated accumulated thermal units (ATUs) for each sensor location; we assumed emergence occurred at 932 ATUs based on the time to $50 \%$ emergence in previous laboratory studies. We found that mixing various proportions of hyporheic and river temperature data from the realtime sensors could be used to reproduce the number of days to emergence for the full range of sensor locations in 2006-2007. The number of days to emergence that were mapped in the Ives Island area were spatially coherent, with much shorter time to emergence in the western part of the channel relative to more easterly parts of the channel. These results are similar to those of earlier studies showing that bed temperatures in the Ives Island area tend to be spatially continuous and mappable and that cooler hyporheic water is found in the eastern part of the channel.

A pre-season estimate of emergence dates is determined by interpolating the days to emergence for each redd location from the map of 2006-2007 redds and temperatures. The map is then used to identify the mixture of hyporheic and river temperature data from the real-time system that would provide the closest match for the estimated days to emergence for each redd location. The identified mixture is then used to update the emergence estimates for each redd during the incubation season as new hyporheic and river temperature data become available from the real-time system. This method assumes that the spatial distribution of areas with warm and cool hyporheic temperatures near Ives Island tends to be relatively constant, as suggested by the results of earlier mapping studies. A case study was prepared using redd location data from 2009-2010 to illustrate use of the conceptual model. The case study showed differences in emergence estimates resulting from variations in the river and hyporheic temperatures from year to year. 


\section{Acronyms and Abbreviations}

$\begin{array}{ll}\text { ATU(s) } & \text { accumulated thermal unit(s) } \\ \mathrm{cm} & \text { centimeter(s) } \\ \mathrm{DTE} & \text { days to emergence } \\ \text { FCRPS } & \text { Federal Columbia River Power System } \\ \mathrm{ft} & \text { foot, feet } \\ \mathrm{h} & \text { hour(s) } \\ \mathrm{km} & \text { kilometer(s) } \\ \mathrm{m} & \text { meter(s) } \\ \mathrm{m} / \mathrm{s} & \text { meters per second } \\ \mathrm{min} & \text { minute(s) } \\ \mathrm{m}^{3} / \mathrm{s} & \text { cubic meters per second } \\ \mathrm{mL} / \mathrm{min} & \text { milliliters per minute } \\ \text { NOAA } & \text { National Oceanic and Atmospheric Administration } \\ \text { ODFW } & \text { Oregon Department of Fish and Wildlife } \\ \text { PNNL } & \text { Pacific Northwest National Laboratory } \\ \text { PSMFC } & \text { Pacific States Marine Fisheries Commission } \\ \text { RPA } & \text { Reasonable and Prudent Alternative } \\ \mathrm{rkm} & \text { river kilometer(s) } \\ \mathrm{s} & \text { second(s) } \\ \text { TMT } & \text { Technical Management Team } \\ \text { TDG } & \text { total dissolved gas } \\ \text { USACE } & \text { U.S. Army Corps of Engineers }\end{array}$




\section{Contents}

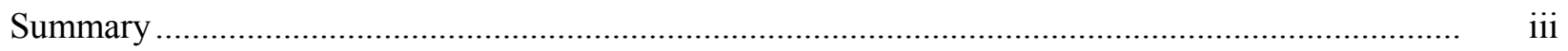

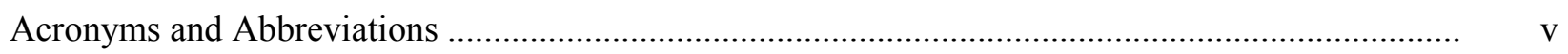

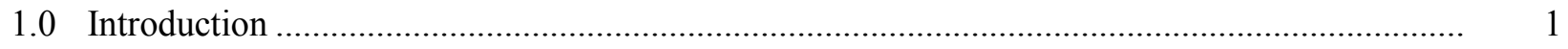

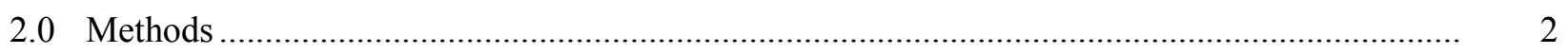

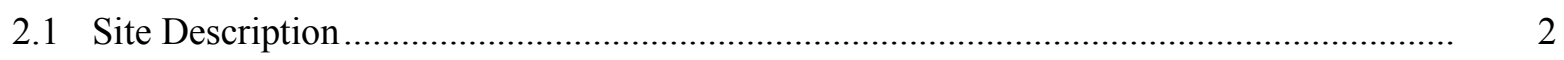

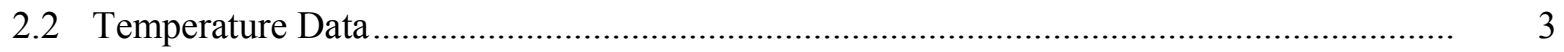

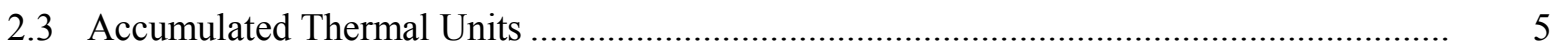

2.4 Chum Salmon Redd Location Data.............................................................................. 6

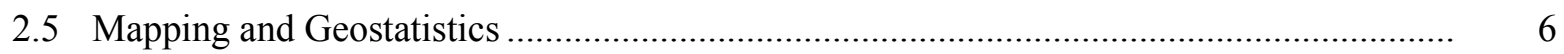

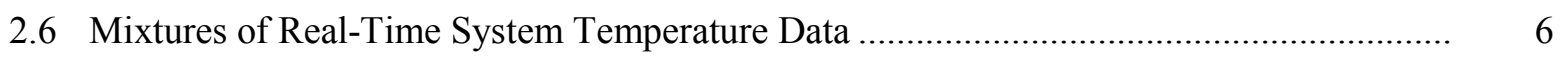

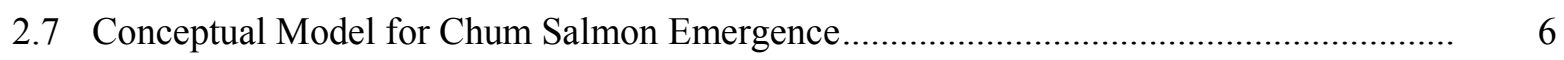

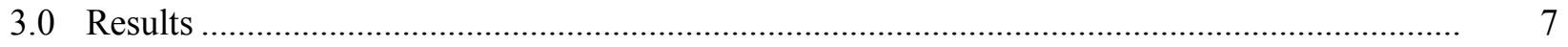

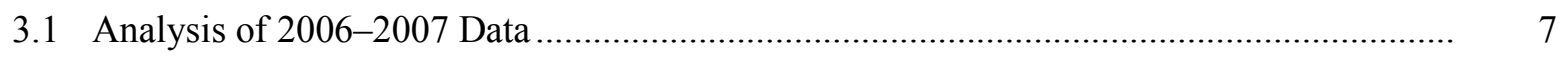

3.2 Case Study - Application of Conceptual Model to 2009-2010 Data ................................ 10

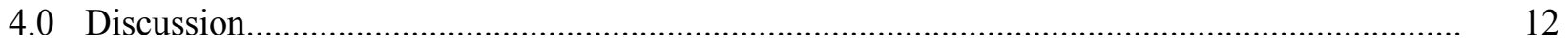

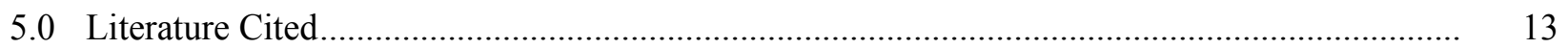

\section{Figures}

1 Location of Ives Island study site downstream from Bonneville Dam on the north side of the Columbia River, Washington

2 Location of real-time temperature data collection sensors within Ives Island chum salmon spawning areas ............................................................................................. 4

3 Onset sensors spaced $10 \mathrm{~m}$ apart on transects within the north channel adjacent to

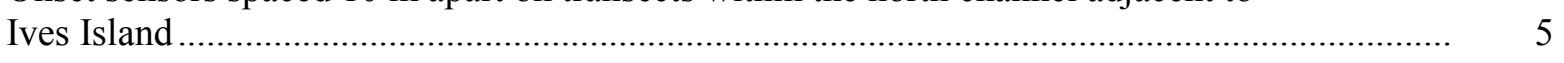

4 The days to emergence for all sensors in the Ives Island north channel during 2006-2007......... 8

5 Data locations showing days to emergence for 2006-2007.................................................. 9

6 Days to emergence for several different initiation dates, spread over approximately 1 month

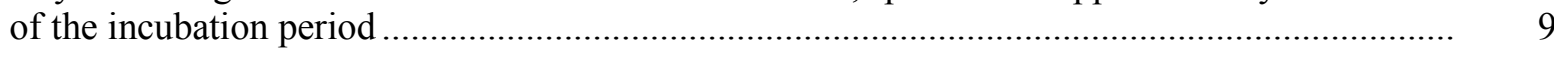

7 Interpolated days to emergence for the 2006-2007 data in the Ives Island study area......

8 Comparison of average daily temperatures for the river and hyporheic sensors at real-time location T1LB. 


\section{Tables}

1 Input parameters and estimated days to emergence for a sample of redds built in 2009.

2 Comparison of statistics of pre-season and in-season estimates of redd emergence for 2009-2010 case study... 


\subsection{Introduction}

Chum salmon (Oncorhynchus keta) spawning and incubation downstream from Bonneville Dam near Ives Island and an associated site near Multnomah Falls collectively represent one of two remaining populations of the Lower Columbia River Evolutionary Significant Unit listed under the Endangered Species Act (NOAA 2008). Chum salmon spawn in the Ives Island area in December, but don't emerge until the spring of the following year. During the period when embryos are incubating in the riverbed gravels, they are susceptible to dewatering from water level changes and to gas bubble disease that results from elevated total dissolved gas (TDG) generated when water is spilled at Bonneville Dam, only about 4 $\mathrm{km}$ upstream of Ives Island. The protection of chum salmon at Ives Island is affected by operation of the entire Federal Columbia River Power System (FCRPS), and the 2008 Biological Opinion (NOAA 2008) requires that tailwater in the Ives Island area be managed to protect incubating fish. For example, the guidelines in Reasonable and Prudent Alternative (RPA) 17 call for a tailwater elevation of $11.5 \mathrm{ft}$ beginning the first week of November (or when chum arrive) and ending by December 31 if forecast indicates that this elevation can be maintained through emergence. The RPA enables the Technical Management Team (TMT) to adapt these tailwater elevations based on fish populations or flow forecast. The TMT process is used to provide recommendations of tailwater elevations through emergence that provides protection of chum salmon. If emergence extends beyond April 10 (when spill begins), then the TMT will evaluate impacts of spill and TDG on incubating chum salmon.

Spill operations occur in the early spring at Bonneville Dam during the time when chum salmon sacfry are still present in the gravel (Arntzen et al. 2009a). These operations include limited spill during March through early April $\left(142 \mathrm{~m}^{3} / \mathrm{s}\right)$ associated with operation of the Bonneville Dam second powerhouse corner collector for passing steelhead kelt, and increased spill beginning approximately April $10\left(2,830 \mathrm{~m}^{3} / \mathrm{s}\right)$ to aid the juvenile salmon downstream migration. Generally, the volume of spill comprises less than $50 \%$ of the total river volume, but during low flow when operators are attempting to balance competing river demands, spill levels vary widely and can comprise up to $75 \%$ of the total river volume (Arntzen et al. 2009a). The state water quality standard used to provide protection for preemergent chum salmon rearing in the gravel has been to limit TDG to $105 \%$ after allowing for depth compensation, i.e., TDG in the river could be as high as $115 \%$ assuming three feet of water depth over the redds (NOAA 1995). The results of a 3-year study conducted from 2006 through 2008 suggested that if water depth over redds in the Ives Island area remained greater than 3 feet deep, then depth compensated TDG remained below 105\% (Arntzen et al. 2007, 2008a, 2009b). However, there were times during the study when adequate depth compensation was not always provided, especially to redds spawned at relatively high riverbed elevations. For example, chum salmon sac-fry were potentially exposed to depthcompensated TDG levels greater than $105 \%$ for up to $170 \mathrm{~h}$ in 2007 and $100 \mathrm{~h}$ in 2008; this represented $4 \%$ to $7 \%$ of the total incubation time in those 2 years. In 2008 , most exposure occurred prior to spring spill when the Bonneville Dam corner collector was operating. This finding contrasts with 2007 results when exposure to elevated TDG was distributed before and after the onset of spring spill.

The U.S. Army Corps of Engineers (USACE) normally operates Bonneville Dam tailwater minimum elevation from the end of spawning until May 15, the assumed end of emergence. One of the recommendations identified in a workshop on chum salmon and TDG (Southard et al. 2009) was that management agencies need to have a reliable and accepted method with which to estimate when chum salmon emergence is completed-"Determine the range of chum salmon emergence, either through collection of empirical data or through application of temperature values, to estimate accumulated thermal 
units" (Southard et al. 2009, p. 26, recommendation 5). If the USACE and TMT had a means to estimate the range of emergence, then difficult decisions on water level management could be made with more information. In the past, fisheries management agencies estimated emergence by using river temperature to determine when the amount of accumulated thermal units (ATUs) had reached a predetermined threshold that was correlated with emergence. The relationship between ATUs and emergence of salmonids is well documented (Piper et al. 1989). Specific to chum salmon, the Pacific Northwest National Laboratory (PNNL) has conducted 2 years of laboratory studies with chum salmon in which researchers documented the range of emergence and the ATU values that corresponded to this range of emergence (Arntzen et al. 2008a, 2009b). In addition, the Washington Department of Fish and Wildlife has considerable information on this subject from its work with lower Columbia River chum salmon (Hillson 2003). Therefore, if the appropriate temperatures to use in a model of emergence could be determined, the prediction of when the fish will emerge would be fairly straightforward.

However, our research over the past several years in the Ives Island area suggests a large difference between river temperature and the temperature at the locations where chum salmon eggs/embryos are placed (Arntzen et al. 2008a, 2009b). In the Ives Island area, there can be significant variations in riverbed temperature within a fairly small area, and this variation in temperature is a function of the spatial heterogeneity of riverbed sediments, groundwater inputs, and tailwater fluctuations (Geist et al. 2002, 2008; Arntzen et al. 2009a). The importance of the relationship between temperature and emergence of chum salmon resulted in the installation of three temperature recording devices that, in real time, keep track of riverbed (i.e., hyporheic) and river temperature and report those values to the Fish Passage Center website (Arntzen et al. 2005). PNNL began collecting hourly temperature data within the hyporheic zone in the Ives Island area during the 1999 spawning year and has collected continuous hourly temperature data from at least three and up to eleven hyporheic locations during the spawning and incubation period each year from 1999 to present day. Complementary river temperature data have been collected since 2001. Thus, temperature data within the riverbed and river have been compiled over a wide range of operating conditions and provide a data set that can be queried to determine the specific relationships between temperature and chum salmon incubation.

The objective of the study described herein was to develop a conceptual model of chum salmon emergence that is based on empirical water temperature of the riverbed and river in specific locations where chum salmon spawn in the Ives Island area. The conceptual model was developed using water temperature data that have been collected in the past and are currently being collected in the Ives Island area. The model will be useful to system operators who need to estimate the complete distribution of chum salmon emergence (first emergence through final emergence) in order to balance chum salmon redd protection and power system operation.

\subsection{Methods}

\subsection{Site Description}

The study site was located $3.5 \mathrm{~km}$ downstream of Bonneville Dam in a side channel of the Columbia River between Ives Island and the right bank (river kilometer [rkm] 229 as measured from the mouth of the Columbia River; Figure 1). The Ives Island channel is immediately downstream of, and receives discharge and sediment input from, Hamilton Creek. The Ives Island channel is about $250 \mathrm{~m}$ long with a 
mean width of $44 \mathrm{~m}$, a longitudinal gradient less than $1 \%$, and water velocities generally less than $1 \mathrm{~m} / \mathrm{s}$ (Garland et al. 2003; Tiffan et al. 2005). River level in the Ives Island channel is influenced by Bonneville Dam discharge, tidal effects from the Pacific Ocean, and backwater effects from the Willamette River, which enters the Columbia River at rkm 162.

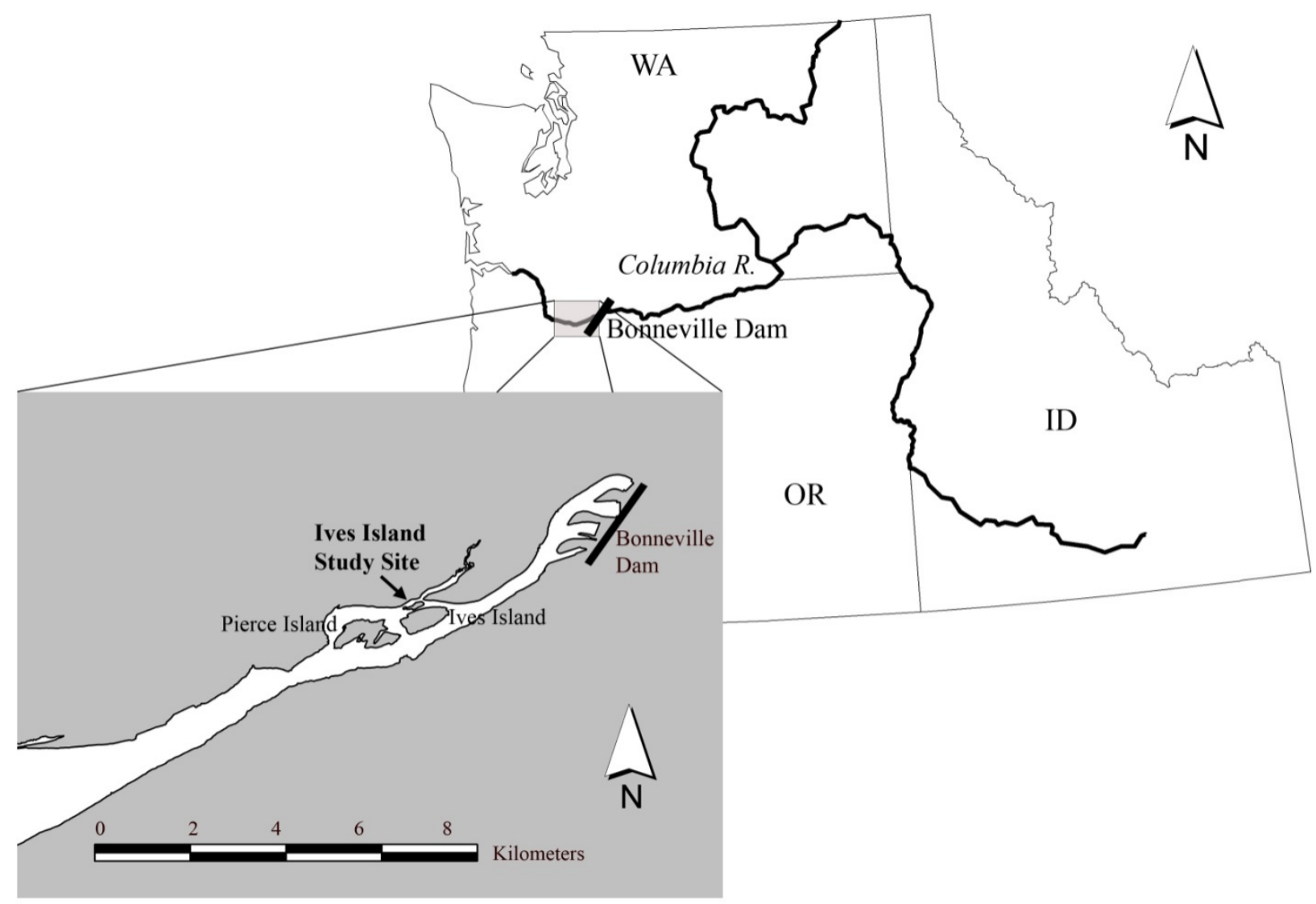

Figure 1. Location of Ives Island study site downstream from Bonneville Dam on the north side of the Columbia River, Washington.

\subsection{Temperature Data}

We used temperature data collected hourly in real time from three monitoring locations in the Ives Island area (Figure 2). At location T1, the left bank side of the channel was monitored; at location T2, both the left bank side of the channel and the middle of the channel were monitored (Figure 2). These locations are referred to as T1LB, T2LB, and T2MC, respectively. Monitoring was conducted using a temperature and water level data collection system that was installed during 2003 and has operated continuously since that time (Arntzen et al. 2005). We relied on data from the real-time system that were collected during 2006-2007 (Arntzen et al. 2008b) and 2009-2010 (PNNL, unpublished data). The realtime data collection system used pressure and temperature sensors (Model PT2X, Instrumentation Northwest, Inc., Kirkland, Washington) at paired locations within the river and riverbed. PT2X sensors record temperature with a resolution of $0.1^{\circ} \mathrm{C}$; water level is recorded with an accuracy of $\pm 0.6 \mathrm{~cm}$. 


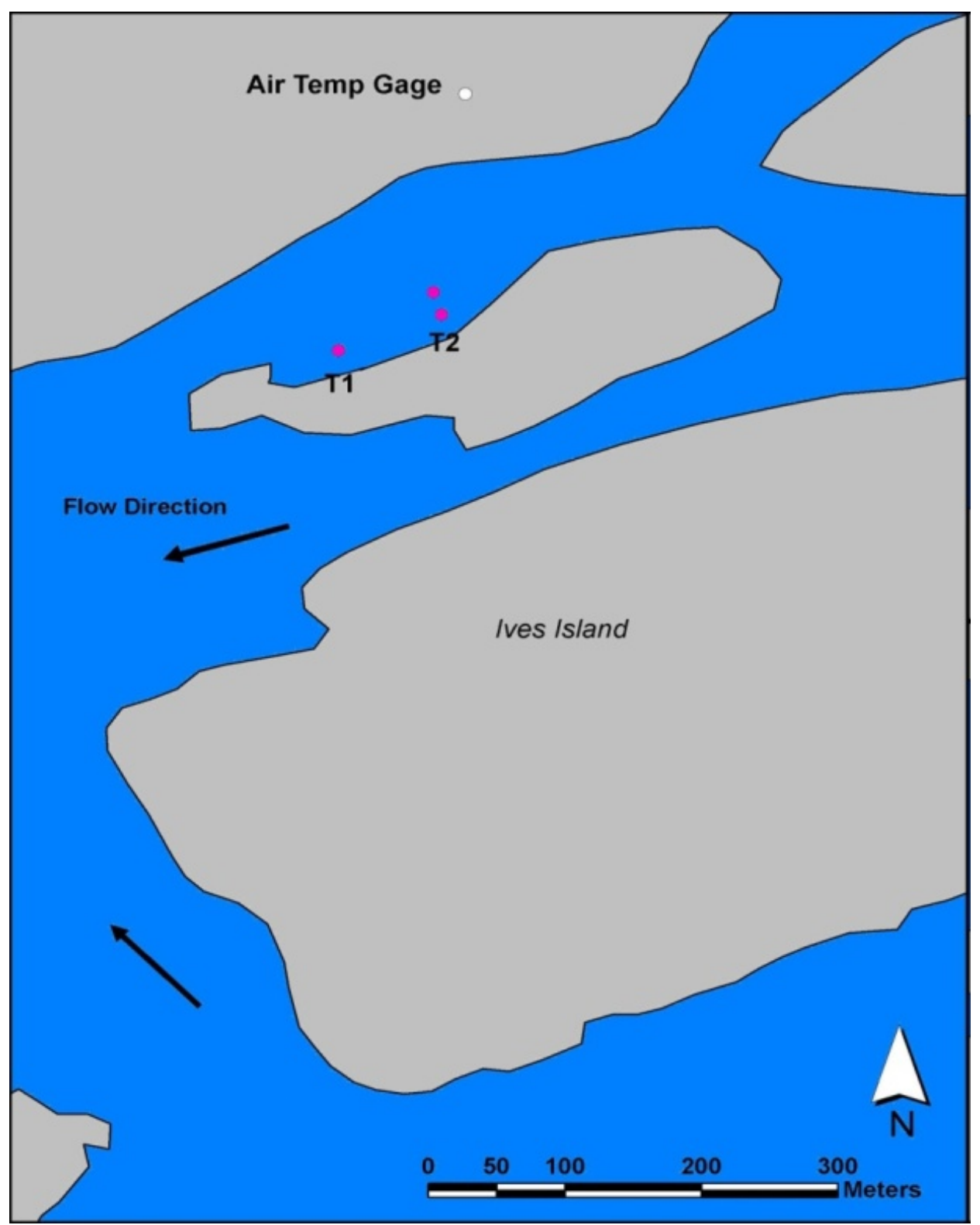

Figure 2. Location of real-time temperature data collection sensors (red circles) within Ives Island chum salmon spawning areas.

We also used additional temperature data that were collected with a network of 33 data loggers (HOBO Water Temp Pro, Onset Computer Corporation, Pocasset, Massachusetts) deployed from October 31, 2006, through September 28, 2007, in chum salmon and fall Chinook salmon (O. tshawytscha) spawning areas within the Ives Island complex (Arntzen et al. 2008b; Figure 3). The data set from the 2006-2007 season was chosen for this study because it had the largest number of sensors with hourly measurements of hyporheic temperatures throughout the incubation period.

Onset sensors were spaced $10 \mathrm{~m}$ apart along transects labeled N1 through N7 and N10 (Figure 3). Onset sensors were deployed with the sensor tip located approximately $20 \mathrm{~cm}$ below the riverbed. Each sensor had a specified accuracy of $\pm 0.02^{\circ} \mathrm{C}$. 


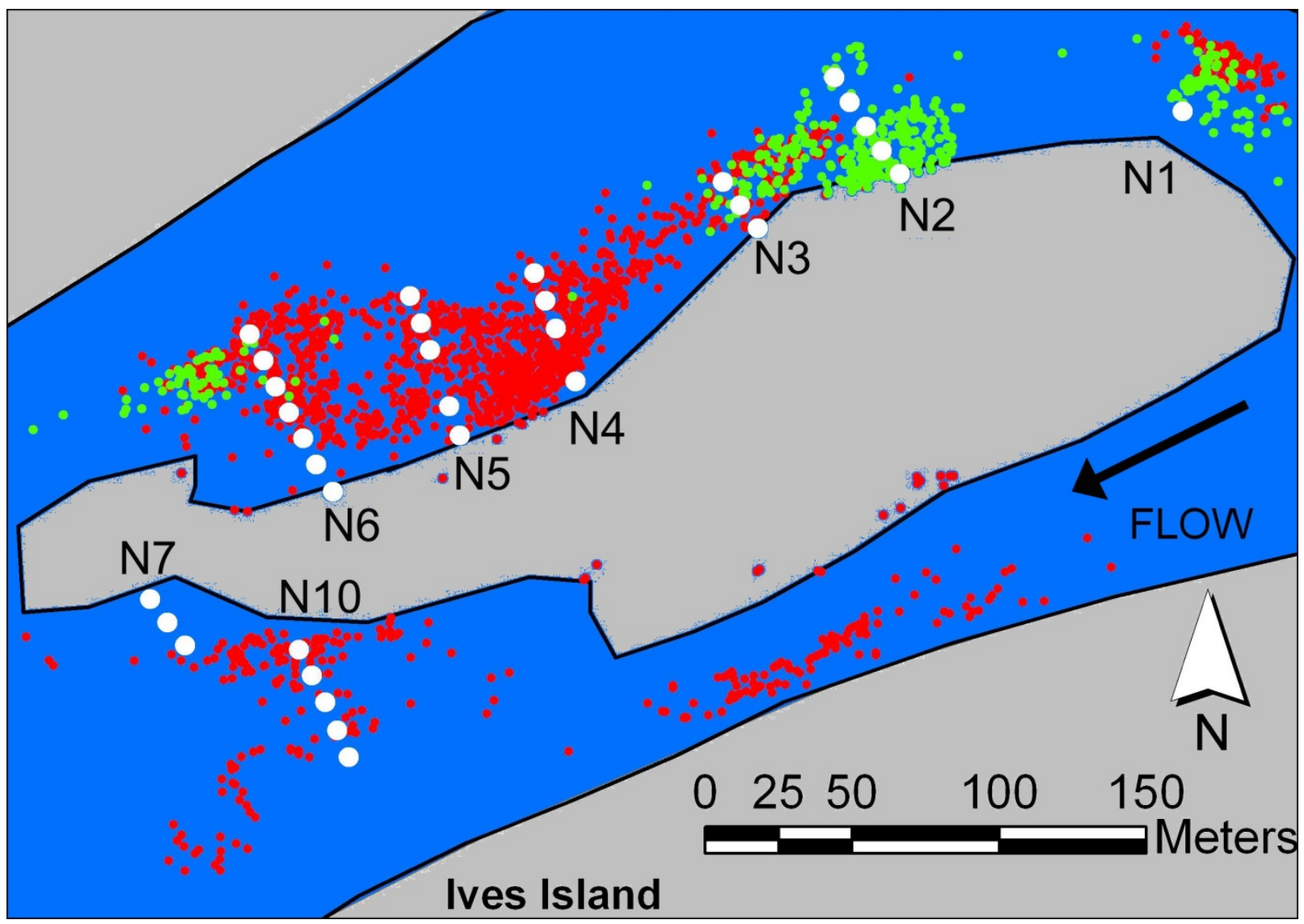

Figure 3. Onset sensors (white circles) spaced $10 \mathrm{~m}$ apart on transects within the north channel adjacent to Ives Island. Redd locations for chum salmon (red circles) are based on redd surveys conducted during 2000-2006. Locations for fall Chinook salmon redds (green circles) are based on surveys conducted during 2000-2004.

\subsection{Accumulated Thermal Units}

The ATUs represent the thermal units that accumulate daily as the embryos develop, with each $1^{\circ} \mathrm{C}$ representative of one thermal unit (i.e., if the daily average temperature were $10^{\circ} \mathrm{C}$, the embryos would accumulate 10 ATUs on day 1, 130 ATUs on day 13, and so on). Our laboratory research from 2007 and 2008 showed that $50 \%$ emergence of chum salmon occurred at an average of 932 ATUs (range 917 to 959 ATUs; Arntzen et al. 2008a, 2009b). The ATUs measured at the time of emergence were based on studies conducted with hatchery chum salmon in our laboratory where we documented the ATUs to the date ( \pm 1 day) when $50 \%$ of the embryos emerged from emergence tubes. Emergence tubes consisted of a light and dark chamber connected to each other via a clear tube. They were constructed of 17-cm-long sections of 5-cm-diameter white and 6.5-cm-diameter clear polyvinyl chloride pipe. Water flow (approximately $600 \mathrm{~mL} / \mathrm{min}$ ) was directed such that it upwelled through gravel of assorted sizes in the bottom of the dark (white) chamber, across the clear tube, and into the light (clear) chamber. Fry emergence occurred when the alevin followed the flow of water toward the light and moved across to the clear chamber of the emergence tube. 


\subsection{Chum Salmon Redd Location Data}

The spatial distribution of chum salmon redds is provided by state agencies each year during weekly surveys conducted from mid-November through the end of December in the Ives Island area. Each week, survey crews (on foot) used a Global Positioning System receiver to mark the locations of new redds in shallow-water areas. These data were provided by the Oregon Department of Fish and Wildlife (ODFW) for spawning year 2006 (ODFW, unpublished data). The spatial distribution of chum salmon redds was provided by the Pacific States Marine Fisheries Commission (PSMFC) for spawning year 2009 (PSMFC, unpublished data).

\subsection{Mapping and Geostatistics}

Standard mapping methods were used in interpolation of the days to emergence data. Ordinary kriging (Isaaks and Srivastava 1989) was used to interpolate the number of days until emergence onto a regular grid in the northern portion of the study area where more data were available. Ordinary kriging is a geostatistical method based on a generalized form of linear regression that allows one to incorporate an explicit model of the spatial variability of a variable. Inverse distance weighting interpolation (Davis 2002) was used for the southern portion of the study area where fewer temperature data were available.

\subsection{Mixtures of Real-Time System Temperature Data}

Analysis of previous studies (Geist et al. 2002, 2008) as well as analysis of the 2006-2007 temperature data (see Section 3) suggest that the interaction and mixing of cool river water and warmer groundwater are major influences on the distribution of water temperatures in the hyporheic zone. We developed artificial mixtures of water temperature data for each of the real-time sensors in an attempt to provide surrogate time series of temperature data for unsampled locations. This was accomplished by creating three new series of temperature data for each real-time sensor location. One mixture consisted of $25 \%$ river water and $75 \%$ groundwater, a second consisted of $50 \%$ river water and $50 \%$ groundwater, and the third consisted of $75 \%$ river water and $25 \%$ groundwater. For example, the first series described above would be calculated by taking $25 \%$ of the river temperature at a given real-time sensor location and adding it to $75 \%$ of the deep groundwater temperature at that location. This provided a total of five hourly series of temperature data for each real-time location, the three mixtures just described, and two series that would be the hourly measurements from the river sensor and the deep groundwater sensor.

\subsection{Conceptual Model for Chum Salmon Emergence}

Based on analysis of the 2006-2007 temperature data (see Section 3), we developed a conceptual model for chum salmon emergence that provided two estimates of the distribution of emergence dates for the redds - a pre-season estimate and an in-season update of that estimate. This conceptual model assumes that the spatial pattern of the days to emergence seen in 2006-2007 will hold true in future years. For simplicity, we also assume complete emergence of all fry from a redd when the estimated ATU value reaches 932 . 


\subsubsection{Pre-Season Estimate}

The pre-season estimate provides an initial estimate based on the spatial extent of the days to emergence for 2006-2007. This estimate would be available as soon as spawning is complete and the locations and spawning dates for the chum salmon redds are known. The pre-season estimate is based on the following steps:

- Gather data on locations for chum salmon redds and their approximate spawning dates.

- Interpolate days to emergence for each redd location using the map of days to emergence from 2006-2007 (this map is based on the distribution of temperature data in that same period).

- Add interpolated days to emergence to the spawning date to arrive at an estimated emergence date for each redd.

- Sort the emergence dates for all of the redds. This sorting provides an estimate of the cumulative distribution of emergence dates.

- Retrieve estimates of important statistics from the distribution of emergence dates; for example, the first date of emergence, the date when $50 \%$ of the redds have emerged, the date when $80 \%$ of the redds have emerged, and so on.

\subsubsection{In-Season Estimate}

The in-season estimate updates the pre-season estimate using new temperature data collected during the incubation season from the real-time sensors at Ives Island. The in-season update of the pre-season estimate using real-time system data is based on the following steps:

- Match the estimated days to emergence for each redd identified in the pre-season estimate to the closest number of days to emergence calculated for the 15 mixture/sensor combinations of river and groundwater temperature data from the real-time system (described in Section 2.6). That match is used to assign a sensor and mixture combination (e.g., T2MC_50\%river) to each redd.

- Monitor the real-time temperature data collected at that sensor location during the incubation season and use that data to determine when that location reaches 932 ATUs, which is the estimated $50 \%$ emergence threshold. The date associated with this threshold is then assigned to that redd as the updated predicted date of emergence.

- Use the updated emergence dates to revise the statistics of emergence during the incubation season.

\subsection{Results}

\subsection{Analysis of 2006-2007 Data}

We calculated ATUs for all locations with hourly temperature data for the 2006-2007 chum salmon incubation period and identified the number of days to emergence based on exceeding the 932-ATU threshold (Figure 4). The days to emergence in 2006-2007 ranged from 71 (T2LB Hyp) to 156 (T2LB River; Figure 4). 


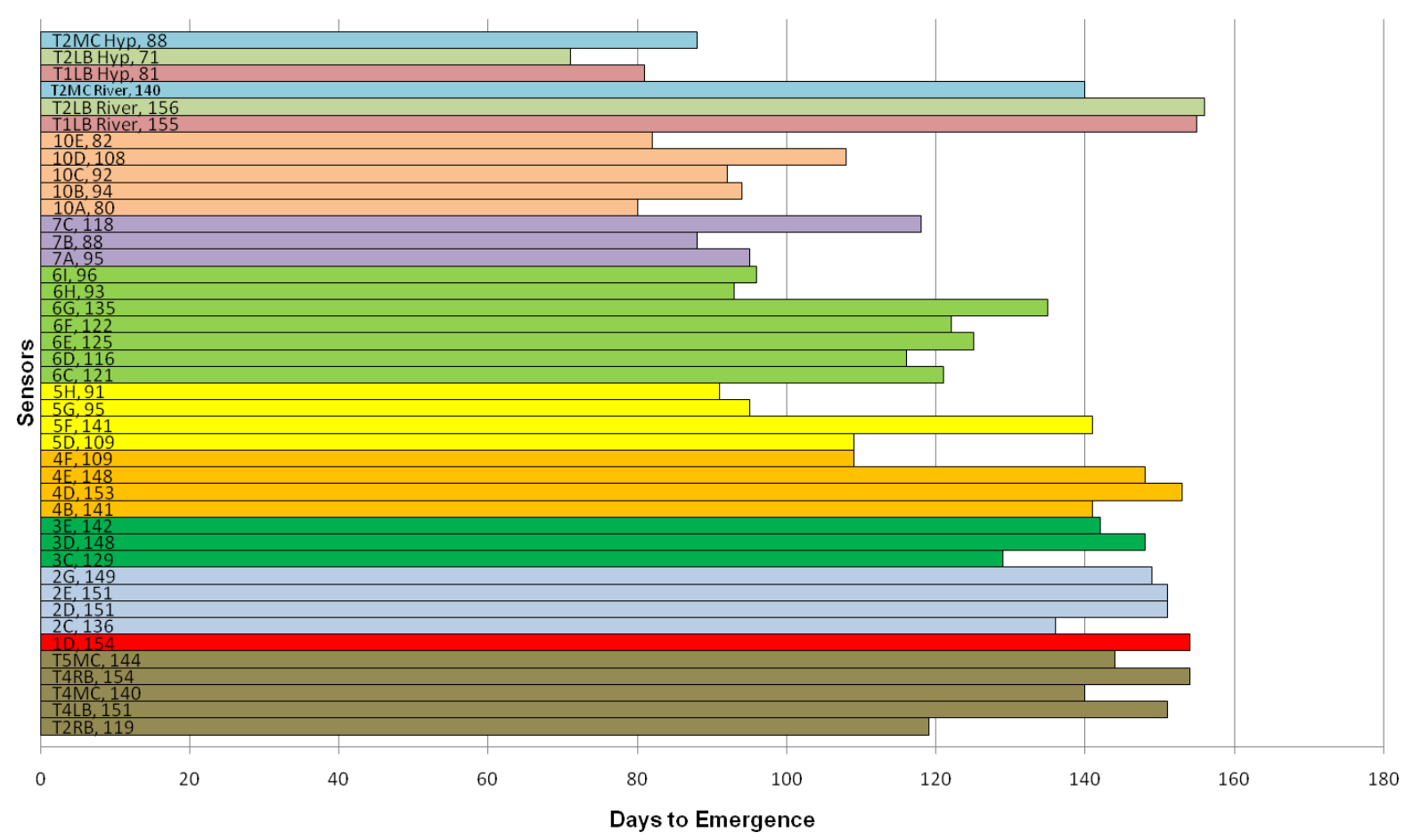

Figure 4. The days to emergence for all sensors in the Ives Island north channel during 2006-2007. The top six lines show the three real-time sensors for the hyporheic zone (Hyp) and the river (River). The rest of the 37 sensors are shown below those. The number of days to emergence for each sensor location is shown in the colored bars following the sensor label. ATUs used to estimate the number of days to emergence were calculated using an initiation date of November 26, which corresponds to the average date when half of the chum salmon redds have been formed. Threshold for emergence was 932 ATUs.

Plotting the days to emergence for the 2006-2007 sensor locations, we found that the data were spatially continuous, with shorter days to emergence in the western portion of the channel and longer periods required in the eastern portion of the channel (Figure 5). The number of days to emergence is inversely correlated to the hyporheic temperatures, indicating that hyporheic temperatures were warmer in the western portion of the study area. This conclusion is supported by previous temperature mapping studies of the Ives Island north channel where little input of warm hyporheic flow in the eastern portions of the channel was observed (Geist et al. 2002).

The stability of the hyporheic temperature regime over time was also demonstrated within the 2006-2007 incubation period. We compared the days to emergence that would be found by using different initiation dates for calculation of the ATUs (Figure 6). The two scatter-plots in Figure 6 show an extremely high positive correlation between the estimated number of days to emergence for initiation dates that are much earlier (the average date for $10 \%$ of spawning to occur) and much later (the $90 \%$ spawning date). If the spatial distribution of water temperature in the area did not remain constant over that period, a scatter-plot of the 50th percentile dates with either the 10th or 90th percentiles would be expected to exhibit much more noise. 


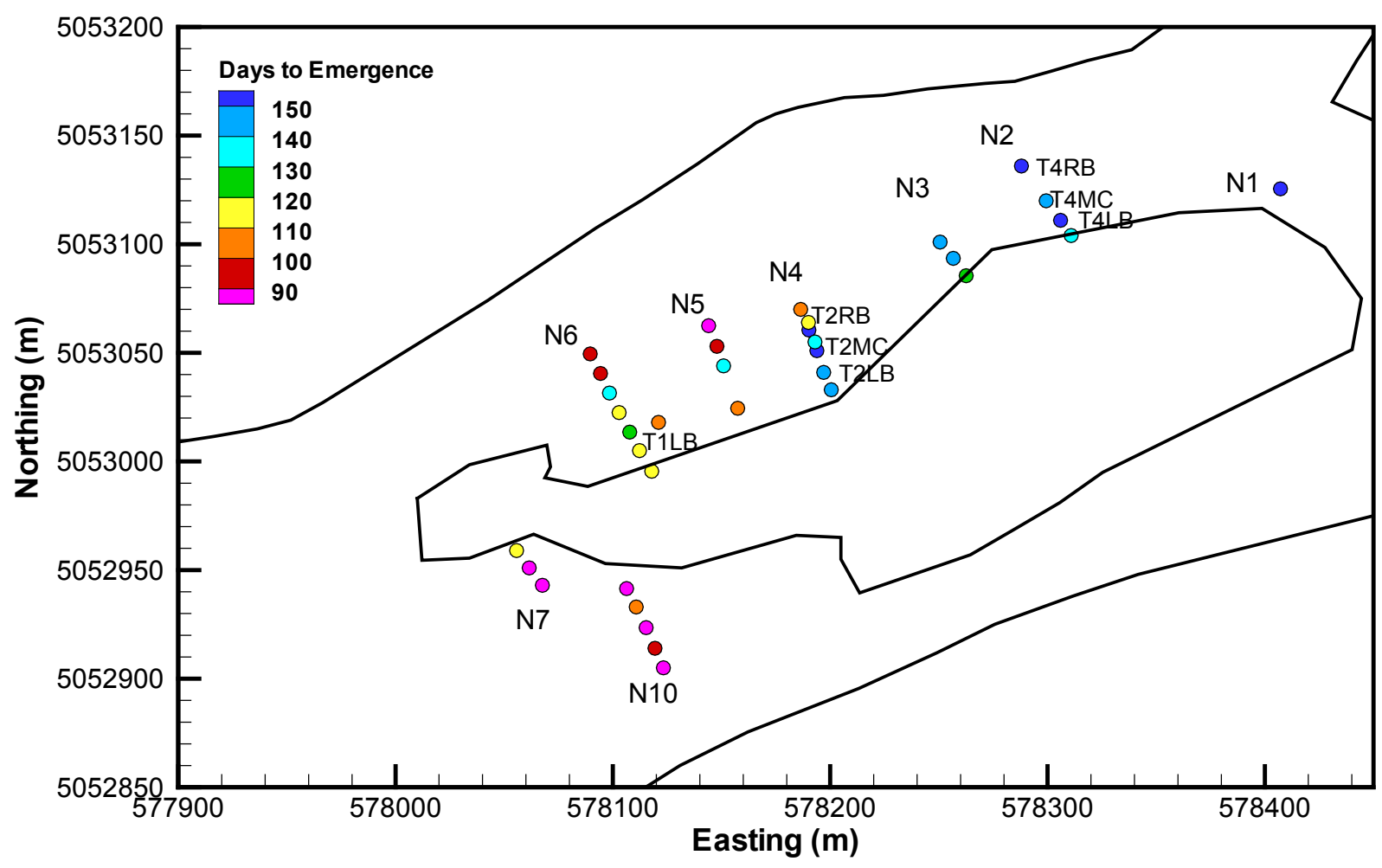

Figure 5. Data locations showing days to emergence for 2006-2007. Days to emergence are based on $50 \%$ spawning date of November 26 and the number of days required to exceed 932 ATUs.
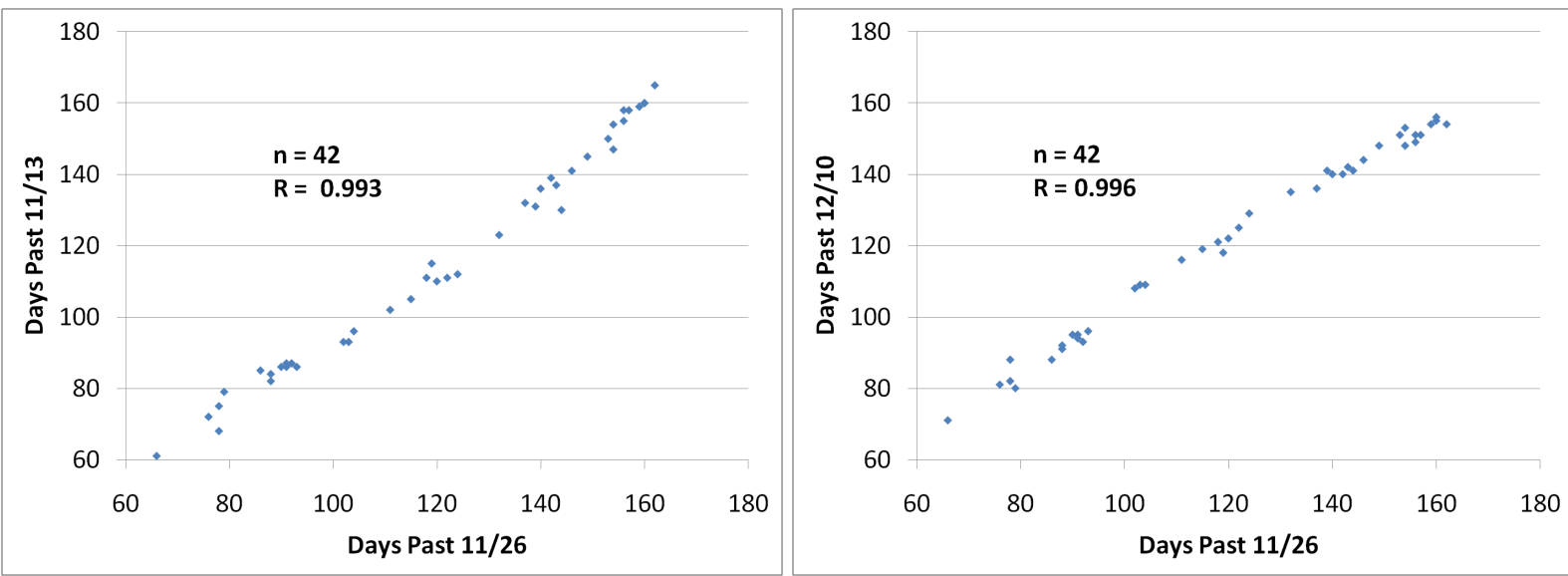

Figure 6. Days to emergence for several different initiation dates, spread over approximately 1 month of the incubation period.

Interpolation of the days to emergence data shown in Figure 5 provided an estimate of the spatial distribution of emergence times for the Ives Island spawning area (Figure 7). This map forms the basis for the conceptual model of emergence described in Section 3.2. 


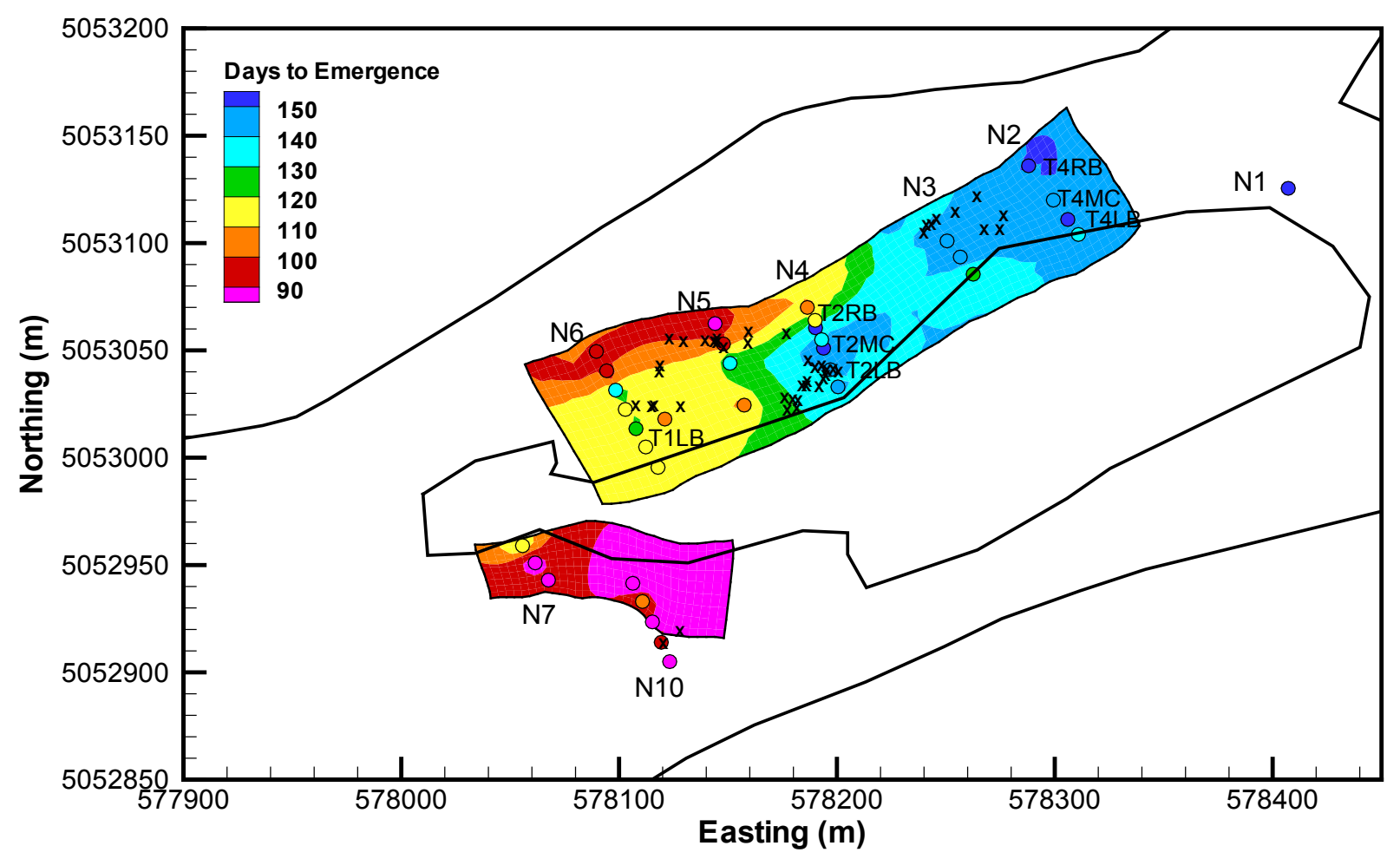

Figure 7. Interpolated days to emergence for the 2006-2007 data in the Ives Island study area. Sensor locations shown as circles; Xs indicate the locations of 2009-2010 chum salmon redds.

\subsection{Case Study - Application of Conceptual Model to 2009-2010 Data}

We applied the conceptual model identified in Figure 7 to generate pre-season and in-season estimates of time to emergence for the 2009-2010 redd locations (i.e., redds built in 2009 that incubate into 2010). The estimated values of the days to emergence for each redd from 2009 were interpolated from the 2006-2007 model at the locations shown in Figure 7. The pre-season estimates were then generated by adding the days to emergence to the spawning date (Table 1 shows a portion of these data).

The interpolated days to emergence from the 2006-2007 map were compared with the calculated days to emergence for the various sensor/mixture combinations; the closest matches were selected and are included in Table 1 (see Site/Mixture). For each 2009-2010 redd, we then used the time series of average daily temperatures for the identified sensor/mixture combination and calculated the ATUs using the spawning date as the date to initiate the sum. The date when the ATUs exceeded 932 for each redd is noted as the In-Season estimate (Table 1). Comparison of the pre-season and in-season estimates for the full population of chum salmon redds in 2009-2010 shows that the average date of emergence predicted by the in-season estimate was 1 to 2 weeks earlier than the pre-season estimate (Table 2). Examination of temperature data from the real-time sensors indicated that both the river temperature and hyporheic temperature were significantly higher in 2009-2010 than they were in 2006-2007 (Figure 8), which would lead to earlier emergence times. 
Table 1. Input parameters and estimated days to emergence (DTE) for a sample of redds built in 2009. The DTE is interpolated from the 2006-2007 map of days to emergence (Figure 7). Site/Mixture is the sensor and mixture with the closest match on the days to emergence. Spawn is the approximate spawning date. Pre-Season and In-Season are the estimated emergence dates using the two methods.

\begin{tabular}{crccccc}
\hline Easting $(\mathrm{m})$ & Northing $(\mathrm{m})$ & DTE & Site/Mixture & Spawn & Pre-Season & In-Season \\
\hline 578118.97 & 5053042.47 & 109.9 & T2MC_50\%riv & $11 / 12 / 09$ & $3 / 1 / 10$ & $2 / 10 / 10$ \\
578176.23 & 5053027.41 & 128.0 & T2MC_75\%riv & $11 / 23 / 09$ & $3 / 31 / 10$ & $3 / 21 / 10$ \\
578179.98 & 5053027.23 & 130.1 & T2LB_75\%riv & $11 / 23 / 09$ & $4 / 2 / 10$ & $3 / 4 / 10$ \\
578181.82 & 5053022.81 & 129.7 & T2LB_75\%riv & $11 / 23 / 09$ & $4 / 1 / 10$ & $3 / 4 / 10$ \\
578182.32 & 5053026.71 & 131.2 & T2LB_75\%riv & $11 / 23 / 09$ & $4 / 3 / 10$ & $3 / 4 / 10$ \\
578186.21 & 5053033.53 & 134.8 & T2LB_75\%riv & $11 / 23 / 09$ & $4 / 6 / 10$ & $3 / 4 / 10$ \\
578191.91 & 5053033.05 & 136.6 & T2LB_75\%riv & $11 / 23 / 09$ & $4 / 8 / 10$ & $3 / 4 / 10$ \\
578193.97 & 5053036.63 & 138.4 & T1LB_75\%riv & $11 / 23 / 09$ & $4 / 10 / 10$ & $3 / 28 / 10$ \\
578195.12 & 5053037.76 & 139.3 & T1LB_75\%riv & $11 / 23 / 09$ & $4 / 11 / 10$ & $3 / 28 / 10$ \\
578195.64 & 5053040.43 & 140.3 & T2MC_river & $11 / 23 / 09$ & $4 / 12 / 10$ & $3 / 29 / 10$ \\
578198.51 & 5053041.24 & 140.7 & T2MC_river & $11 / 23 / 09$ & $4 / 12 / 10$ & $3 / 29 / 10$ \\
\hline
\end{tabular}

Table 2. Comparison of statistics of pre-season and in-season estimates of redd emergence for 2009-2010 case study.

\begin{tabular}{lcc}
\hline Emergence & Pre-Season & In-Season \\
\hline Earliest & $3 / 1 / 2010$ & $2 / 10 / 2010$ \\
$10 \%$ & $3 / 11 / 2010$ & $3 / 4 / 2010$ \\
$50 \%$ & $4 / 8 / 2010$ & $3 / 25 / 2010$ \\
$90 \%$ & $4 / 23 / 2010$ & $4 / 9 / 2010$ \\
\hline
\end{tabular}
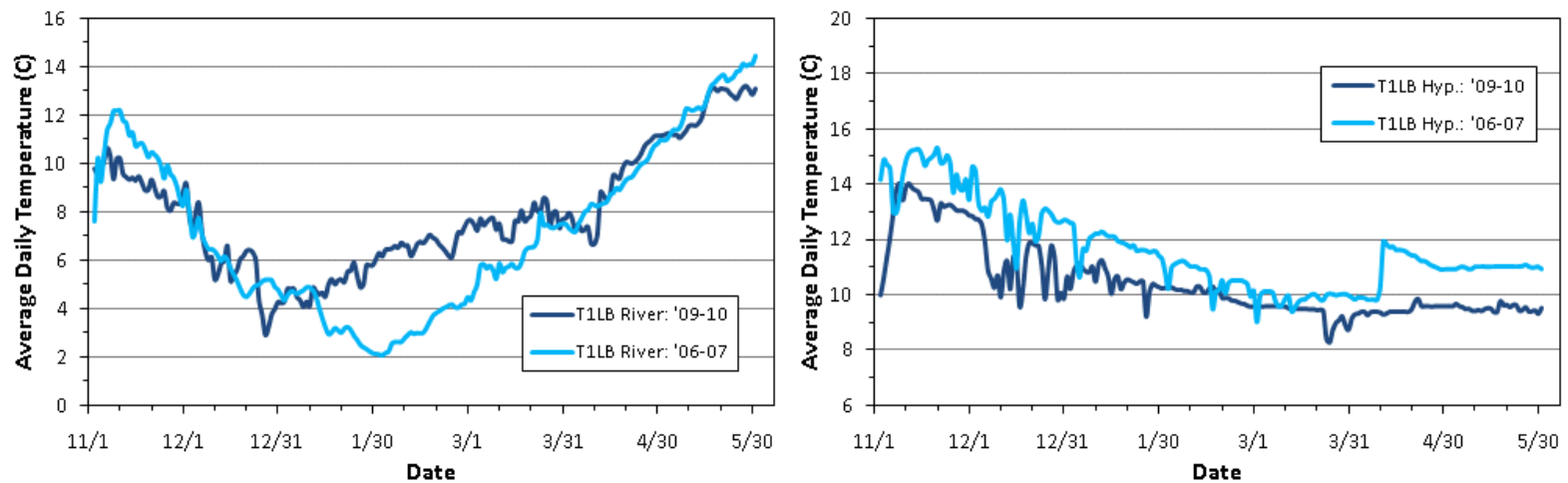

Figure 8. Comparison of average daily temperatures for the river (left) and hyporheic (right) sensors at real-time location T1LB. 


\subsection{Discussion}

A method has been developed to provide more complete estimates of chum salmon redd emergence for the Ives Island area, providing estimates of the full temporal distribution from first emergence to final emergence. Those estimates reflect the influence of redd location and the spatial pattern of groundwater temperatures. The pre-season estimate should provide a good preliminary estimate of the distribution of emergence dates that would be available very soon after spawning is complete. The in-season update of the estimate accounts for significant inter-annual variation of river and groundwater temperature. The results for the 2009-2010 case study demonstrate that significant differences in emergence could occur from year to year, in part from variations in river and hyporheic temperatures. In addition, variations in emergence timing could depend, in part, on variations in the locations where chum salmon spawn. For example, an eastward shift of spawning locations in the channel would be expected to increase the number of days to emergence (Figure 7).

The proposed estimation methods rely heavily on the assumption that the spatial patterns of groundwater temperature are stable over time in the Ives Island area, and comparison of the results of this study with earlier efforts (e.g., Geist et al. 2002) suggests this is a reasonable assumption. However, field work could be used to examine that assumption by repeating the widespread temperature logging experiments that were performed in 2006-2007. These measurements might also be used to extend the coverage of the map of days to emergence to other sites in the Ives Island area where chum salmon are known to spawn. The proposed estimation method also relies heavily on the accurate annual determination of where and when chum salmon spawn in the Ives Island area, and also on the collection of river and riverbed temperature during the incubation period. Absent this information, the model will be forced to rely on historical information and its predictive power may be significantly reduced.

Direct evaluation of the value of the predictions prepared using the proposed methods would be possible by field observations of chum salmon emergence that could include seining and/or redd capping. Such studies would help increase the confidence in the proposed estimation methods.

Differences in the number of temperature units required for hatching and development of chum salmon have been shown to vary widely within stocks due to temperature (weather) as well as other local factors, such as the quality of the gravel environment, nutritional condition of the adults and embryos, and even the behavior of alevins in the gravel (reviewed in Bakkala 1970; Salo 1991). Differences among stocks also are common and depend on long-range temperature characteristics that differ between northern and southern climates (Koski 1977; Salo 1991). As a consequence of these variations, the range in temperature units that results in emergence among chum salmon stocks is huge and lies somewhere between 700 and 1,000 temperature units (see Table 4, page 248 in Salo 1991).

Our emergence model is sensitive to the ATUs used to represent when emergence occurs. Using the model developed in this report, Arntzen and Murray (2011) predicted that emergence would be 13 days earlier if 825ATUs were used as the threshold for emergence instead of 932 ATUs. The 825-ATU value has been used in the past as representative of the earliest onset of emergence in the Ives Island area (personal communication with Todd Hillson, WDFW, as cited in Arntzen and Murray 2011). We chose to use 932 ATUs as the threshold of emergence because it represented when $50 \%$ of the fry from a local chum salmon stock emerged in a controlled study conducted in our laboratory in 2007 and 2008 (Arntzen et al. 2008a, 2009b). In those studies, we documented 50\% emergence of untreated fish over a range of 
917 to 959 ATUs and 100\% emergence of untreated fish over a range of 967 to 975 ATUs (PNNL, unpublished data). The 932 ATU value equates to around 100 days post-fertilization at a mean incubation temperature of $10^{\circ} \mathrm{C}$. Murray and Phail (1988) determined that $50 \%$ of chum salmon emerged in about 98 days after fertilization when incubated at a mean temperature of $11^{\circ} \mathrm{C}$. In our laboratory studies in 2007 and 2008, we found that the onset of emergence was much earlier than the date of $50 \%$ emergence but believe the $50 \%$ emergence date to be a better representation of emergence characteristics of this population than the onset of emergence. The $50 \%$ emergence threshold is also the numeric threshold used in most studies of salmon development (Salo 1991).

In conclusion, we have developed a conceptual model of chum salmon emergence based on the use of empirical water temperature of the riverbed and river in specific locations where chum salmon spawn in the Ives Island area. The conceptual model was developed using water temperature data that have been collected in the past and are currently being collected in the Ives Island area using the real-time system. The model will be useful to system operators who need to estimate the complete distribution of chum salmon emergence (first emergence through final emergence) in order to balance chum salmon redd protection and power system operation.

\subsection{Literature Cited}

Arntzen EV, DR Geist, TP Hanrahan, KE McGrath, and SL Thorsten. 2005. Summary of Temperature Data Collected to Improve Emergence Timing Estimates for Chum and Fall Chinook Salmon in the Lower Columbia River - Progress Report, FY 1999-2004. DOE/BP-00000652-27, Bonneville Power Administration, Portland, Oregon.

Arntzen EV, DR Geist, JL Panther, and EM Dawley. 2007. Total Dissolved Gas Monitoring in Chum Salmon Spawning Gravels Below Bonneville Dam. PNNL-16200, Pacific Northwest National Laboratory, Richland, Washington.

Arntzen EV, KD Hand, DR Geist, KJ Murray, JL Panther, VI Cullinan, EM Dawley, and RA Elston. 2008a. Effects of Total Dissolved Gas on Chum Salmon Fry Incubating in the Lower Columbia River. PNNL-17132, Pacific Northwest National Laboratory, Richland, Washington.

Arntzen EV, RP Mueller, KJ Murray, and Y-J Bott. 2008b. Evaluation of Salmon Spawning Below Bonneville Dam - Annual Report, October 2006-September 2007. Document ID \#P107674, Bonneville Power Administration, Portland, Oregon.

Arntzen EV, DR Geist, KJ Murray, J Vavrinec, EM Dawley, and DE Schwartz. 2009a. Influence of the hyporheic zone on supersaturated gas exposure to incubating chum salmon. North American Journal of Fisheries Management 29:1714-1727.

Arntzen EV, KD Hand, KM Carter, DR Geist, KJ Murray, EM Dawley, VI Cullinan, RA Elston, and J Vavrinec III. 2009b. Total Dissolved Gas Effects on Incubating Chum Salmon Below Bonneville Dam. PNNL-18081, Pacific Northwest National Laboratory, Richland, Washington. 
Arntzen EV and KJ Murray. 2011. Temperature and Water Depth Monitoring within Chum Salmon Spawning Habitat below Bonneville Dam - Annual Report, October 2009-September 2010. Bonneville Power Administration, Portland, Oregon.

Bakkala RG. 1970. Synopsis of biological data on the chum salmon, Oncorhynchus keta (Walbaum 1792). FAO Fisheries Synopsis 41; Circular 315, U.S. Fish and Wildlife Service, Conservation Library, Shepherdstown, West Virginia.

Davis JC. 2002. Statistics and Data Analysis in Geology. John Wiley \& Sons, Inc., New York.

Garland RD, KF Tiffan, DW Rondorf, JJ Skalicky, and DR Anglin. 2003. Evaluation of Fall Chinook and Chum Salmon Spawning Habitat near Ives and Pierce Islands in the Columbia River - Progress Report, 1999-2001. DOE/BP-00004701-1, Bonneville Power Administration, Portland, Oregon. Available at www.efw.bpa.gov/Publications/I00004701-1.pdf (December 2010).

Geist DR, TP Hanrahan, EV Arntzen, GA McMichael, CJ Murray, and Y-J Chien. 2002.

Physicochemical characteristics of the hyporheic zone affect redd sites of chum salmon and fall Chinook salmon in the Columbia River. North American Journal of Fisheries Management 22:1077-1085.

Geist DR, EV Arntzen, CJ Murray, KE McGrath, Y-J Bott, and TP Hanrahan. 2008. Influence of river level on temperature and hydraulic gradients in chum and fall Chinook salmon spawning areas downstream of Bonneville Dam, Columbia River. North American Journal of Fisheries Management $27: 30-41$.

Hillson T. 2003. Re-Introduction of Lower Columbia River Chum Salmon into Duncan Creek. DOE/BP-00007373-2, Bonneville Power Administration, Portland, Oregon.

Isaaks EH and RM Srivastava. 1989. An Introduction to Applied Geostatistics. Oxford University Press, New York.

Koski KV. 1975. The survival and fitness of two stocks of chum salmon (Oncorhynchus keta) from egg deposition to emergence in a controlled-stream environment at Big Beef Creek. Doctoral thesis, University of Washington, Seattle.

Murray CB and JD McPhail. 1988. Effect of incubation temperature on the development of five species of Pacific salmon (Oncorhynchus) embryos and alevins. Canadian Journal of Zoology 66:266-273.

NOAA. 1995. Item 2. Pages 104-110 in Endangered Species Act - Section 7, Consultation, Biological Opinion, Federal Columbia River Power System (FCRPS), National Oceanic and Atmospheric Administration, National Marine Fisheries Service, Northwest Regional Office, Seattle, Washington.

NOAA. 2008. Endangered Species Act - Section 7, Consultation, Biological Opinion, consultation on remand for operation of the Federal Columbia River Power System and 19 Bureau of Reclamation projects in the Columbia River Basin (National Wildlife Federation versus National Marine Fisheries Service, Civil Case Number 01-640-RE [May 5, 2008; revised and reissued pursuant to court order]). National Oceanic and Atmospheric Administration, National Marine Fisheries Service, Northwest Regional Office, Seattle, Washington. 
Piper RG, IB McElwain, LE Orme, JP McCraren, LG Fowler, and JR Leonard. 1989. Fish Hatchery Management. American Fisheries Society, Bethesda, Maryland.

Salo EO. 1991. Life history of chum salmon, Oncorhynchus keta. In Pacific Salmon Life Histories, C Groot and L Margolis (eds), pp. 231-309. University of British Columbia Press, Vancouver, British Columbia, Canada.

Southard SL, DR Geist, EV Arntzen, KM Carter, and GE Johnson. 2009. Proceedings of the 2008 Workshop on Total Dissolved Gas and Chum Salmon - December 2, 2008 - Stevenson, Washington. PNNL-SA-64358, Pacific Northwest National Laboratory, Richland, Washington.

Tiffan KF, DW Rondorf, and JJ Skalicky. 2005. Diel spawning behavior of chum salmon in the Columbia River. Transactions of the American Fisheries Society 134:892-900. 


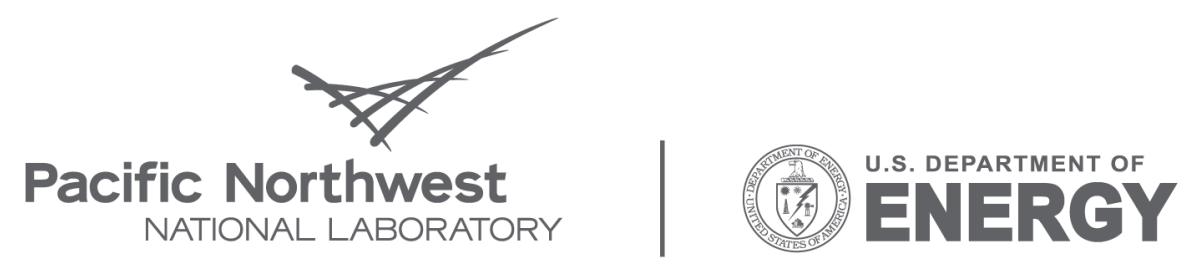

Proudly Operated by Battelle Since 1965

902 Battelle Boulevard

P.O. Box 999

Richland, WA 99352

1-888-375-PNNL (7665)

www.pnl.gov 